\title{
UM DESAFIO PARADOXAL: O OLHAR DE PROFESSORES INICIANTES SOBRE A INSERÇÃO PROFISSIONAL NA PRÁTICA DOCENTE
}

\author{
Márcea Andrade Sales ${ }^{1}$, Ginaldo Cardoso de Araújo ${ }^{2}$ \\ ${ }^{1}$ Doutora em Educação pela Universidade Federal da Bahia - FACED-UFBA, Docente da Universidade do Estado da \\ Bahia - UNEB, Departamento de Educação, Salvador, BA. E-mail: masales@uneb.br \\ ${ }^{2}$ Doutorando em Educação na Universidade Federal de Minas Gerais - UFMG., Docente da Universidade do Estado da \\ Bahia - UNEB, Professor da Rede Estadual de Ensino (Guanambi/BA). E-mail: garaujo@uneb.br
}

\section{RESUMO}

Este texto coloca em pauta o tema da inserção profissional na carreira docente, tendo como fio condutor das discussões o seguinte questionamento: como professores iniciantes veem a inserção profissional na prática docente? Para o debate, recorremos às informações produzidas em pesquisa realizada em Programa stricto sensu com professores recém-formados que estão no exercício da docência em escolas públicas de Ensino Fundamental II e Ensino Médio. Fazendo um recorte desse estudo, buscamos, neste texto, analisar as percepções desses professores sobre a prática docente no percurso de inserção profissional no magistério. Os diálogos com a literatura da área e a análise interpretativa das informações de pesquisa evidenciaram que os professores iniciantes veem os primeiros anos na docência marcados por desafios e contradições: ao mesmo tempo em que estão licenciados/formados pela Universidade, têm que aprender a docência exercitando-a, na escola, no início da carreira; chegam ao ambiente escolar ávidos por mudanças e inovações, mas deparam com discursos e práticas institucionalizados que contrapõem o pensamento dos principiantes, revelando um distanciamento entre os saberes da formação inicial e as demandas da escola real, bem como a complexidade do ser professor na contemporaneidade. Com este texto, portanto, pretendemos potencializar e ampliar o debate sobre a temática na Universidade e nas instituições da Educação Básica.

Palavras-chave: Professores Iniciantes. Prática Docente. Complexidade do Ser Professor.

\section{A PARADOXAL CHALLENGE: the newly teachers look at the professional insertion in teaching practice}

\begin{abstract}
A PARADOXAL CHALLENGE: the newly teachers look at the professional insertion in teaching practice.

The text is on the agenda of the professional insertion in the teaching career, having as leading theme the discussions about the following question: how do the newly graduated teachers see the professional insertion process in the teaching practice? For the discussion, we take a look at the informations produced by a Stricto sensu research program conducted with teachers recent graduated, who are teaching in public schools of Elementary School II and High School. Taking a clipping of this study, we intend, in this text, to analyze the perceptions of these teachers about the teaching practice in the course of professional insertion in the teaching profession. The literature dialogues about this discussion spectrum and the interpretative analysis of the research informations showed that the teachers see the first years in teaching by marked by challenges and contradictions: at the same time that they are graduated / formed by the University, they have to learn about the teaching exercising by doing it, at the school, early in their career; but they are faced with institutional discourses and exercises that counterposed their thought, revealing the distancing between their early graduation knowledges and the real school demands, as well as the teaching complexity in contemporary. With this text, therefore, we intend to potentialize and expand the debate on this thematic in the University and in the institutions of Basic Education.
\end{abstract}

Keywords: Newly Teachers. Teaching practice. The teachers complexity. 


\section{INTRODUÇÃO}

Com o crescimento das pesquisas educacionais dos últimos anos, principalmente no campo da formação e do desenvolvimento profissional de professores, muitos pesquisadores têm se empenhado no estudo da iniciação do professor na carreira docente, apresentando importantes contribuições para o debate científico do tema. Assim, é importante buscar na literatura da área as recentes produções sobre a temática, a fim de verificar sob quais lentes teóricas esses estudos estão encaminhando as discussões. Alves-Mazzotti (1999, p. 182) destaca que "[...] é a familiaridade com o estado do conhecimento na área que torna o pesquisador capaz de problematizar o tema e de indicar a contribuição que seu estudo pretende trazer a expansão do conhecimento".

Estudos como os de Cavaco (1999), Marcelo Garcia (2010; 2011), Huberman (2000), Guarnieri (2005), Papi (2011), Tardif (2014), Calil e André (2016), André (2017) mostram que os primeiros anos da iniciação na docência representam uma etapa importante para a construção do ser professor. Nesse processo, os docentes no início da carreira passam por fases que se caracterizam pela "[...] sobrevivência, descobrimento, aprendizagem e transição" (GARCIA, 2011, p. 09). É "um período realmente importante na história profissional do professor determinando inclusive seu futuro e sua relação com o trabalho". (TARDIF, 2014, p. 9). De modo geral, essas pesquisas têm como foco o professor, estudando a sua formação inicial, a sua prática pedagógica, a construção de sua identidade, a socialização profissional, os dilemas, as tensões, os sucessos e as iniciativas de acompanhamento e apoio no início da profissão docente.

Os primeiros anos da carreira profissional do professor, na perspectiva de Cavaco (1999), é um tempo de instabilidade, insegurança, mas também de aceitação de desafios, em que o docente cria novas relações profissionais. Segundo a autora, trata-se de um período de tensões e desequilíbrios; de reorganizações frequentes e ajustamentos progressivos das expectativas e aspirações ocupacionais ao universo profissional.

Hubermam (2000) em suas pesquisas sobre ciclo de vida profissional dos professores mostra que os docentes apresentam anseios, expectativas, necessidades, satisfação ou insatisfação em variados momentos de suas carreiras. Para o autor, a etapa da entrada na carreira - de um a três anos - é marcada por aspectos de sobrevivência, descoberta e exploração. Há o confronto inicial com a complexidade da profissão, o entusiasmo com o início da carreira e a exaltação pela responsabilidade assumida, além da exploração, que pode ser fácil ou problemática, e se restringe ao campo das questões institucionais.

Esse autor destaca, ainda, que o desenvolvimento da profissão não acontece do mesmo modo para todos os professores. Para alguns, esse percurso é tranquilo, porém para outros pode acontecer cercado de dúvidas, angústias e conflitos. Assim, o desenvolvimento da carreira constitui-se em "[...] um processo e não em uma série de acontecimentos. Para alguns, este processo pode parecer linear, mas para outros, há patamares, regressões, becos sem saída, momentos de arranque, descontinuidades". (HUBERMAN, 2000, p.38)

Guarnieri (2005) ressalta que uma parte do aprendizado da profissão docente só ocorre e só se inicia em exercício. Assim, "[...] o exercício profissional é condição para consolidar o processo de tornar-se professor" (GUARNIERI, 2005 , p. 09). Dito de outro modo, a construção da docência acontece à medida que o professor vai efetivando a articulação entre o conhecimento teórico-acadêmico da formação inicial e o contexto escolar com a prática docente. Outro aspecto mencionado pela autora é que os professores iniciantes não encontram espaços para o desenvolvimento do trabalho coletivo na escola e, assim, organizam suas atividades pedagógicas e sua formação de modo isolado. Lima (2004) reforça essa ideia ao dizer que os próprios professores iniciantes se responsabilizam individualmente por esse processo.

Para Tardif (2014), a iniciação do docente na carreira do magistério é acompanhada, também, de uma fase crítica, uma vez que é a partir das certezas e desdobramentos da experiência prática que os professores avaliam sua formação na Universidade. Desse modo, percebem que muita coisa da profissão se aprende pela experiência, tateando e descobrindo no próprio exercício do trabalho.

Assim, o fazer pedagógico se apresenta, na contemporaneidade, como uma atividade complexa para todos os docentes, principalmente, para aqueles que estão iniciando na carreira. Vaillant e Marcelo Garcia (2012, p. 92) nos dizem que "[...] aprendemos a ser docentes 
quando somos conscientes do que fazemos e do porquê o fazemos; quando damos razões e refletimos sobre as origens e consequências de nossas condutas e das dos demais". Para Calil e André (2016), os professores iniciantes se deparam com um cenário bastante complexo no início da carreira docente porque necessitam dominar conteúdos específicos e transformá-los em pedagógicos, de modo a atender às necessidades dos alunos. Com a intenção de agregar mais informações ao nosso estudo sobre a inserção de professores na carreira docente, recorremos às produções acadêmicas do GT 08 Formação de professores - no âmbito da Associação Nacional de Pós-graduação e Pesquisa em Educação (ANPEd) para verificar o posicionamento de pesquisas recentes sobre o tema.

Na busca feita no GT 08 da ANPEd Formação de Professores -, utilizamos como critério de seleção os trabalhos que apresentassem no título alguma referência ao tema, como professor iniciante, professor principiante, inserção profissional na docência. Fizemos um recorte temporal e trabalhamos com as Reuniões Científicas Nacionais realizadas entre os anos de 2005 (28a ) e 2017 (38무). A justificativa para esse recorte de tempo é que os estudos sobre o tema são recentes e as pesquisas dos últimos congressos podem trazer resultados mais consistentes. Entre trabalhos e pôsteres apresentados, encontramos um total de 388 publicações, nesse período, no GT 08. Desse total, $29(7,47 \%)$ das produções faziam referência ao tema. É um número pequeno, ainda, mas com indicativo de crescimento, uma vez que nas duas últimas Reuniões foram apresentados 12 trabalhos. Após a leitura dos resumos dessas produções, quatro foram selecionadas para leitura completa.

O trabalho de Papi (2011) investigou a constituição do desenvolvimento profissional de professores iniciantes considerados bemsucedidos no exercício da profissão. A pesquisa foi feita com duas professoras, tidas no contexto escolar em que atuavam como bem-sucedidas. Os dados da pesquisa, segundo a autora, permitiram constatar a existência de pressupostos coerentes com o sistema capitalista que interferem como determinantes no processo de desenvolvimento profissional das duas professoras, como o esforço individual para atingir os resultados esperados e a ascensão social representada pelo acesso à profissão.
As professoras bem-sucedidas se inserem em um quadro social no qual é valorizada a capacidade do próprio sujeito para buscar alternativas que levem ao alcance dos resultados impostos pelo sistema educacional. As duas professoras assumem e respondem às prescrições a que estão sujeitas, deixando de explicitar a percepção crítica dos múltiplos condicionantes da ação pedagógica (PAPI, 2011).

Machado (2015) buscou investigar os elementos de consenso das representações sociais do ser professor construídos pelos docentes iniciantes de educação infantil e de ensino fundamental. A pesquisa envolveu 70 professores das redes municipais e estadual da Região Metropolitana de uma capital situada no Nordeste. Com base nos resultados, a autora aponta que a representação social do professor está associada a fatores negativos, como o pessimismo, a indisposição e um sentimento de mal-estar na carreira. As situações que trazem satisfação e desejo de permanecer na docência foram pontuais e discretas nas respostas dos professores iniciantes investigados.

O trabalho de Silva (2017) buscou compreender como ocorre o processo de tornarse docente no início de carreira, identificando suas dificuldades e descobertas. Para tanto, numa primeira etapa, aplicou 658 questionários, sendo 374 no Distrito Federal e 284 em Goiânia para investigar as dificuldades e descobertas de professores iniciantes da rede pública desses dois municípios. Além disso, numa segunda etapa, realizou 75 entrevistas semiestruturadas com professores com cerca de três anos de ingresso na carreira docente pública.

Os resultados dessa pesquisa sinalizaram que muitos professores iniciam a carreira na rede pública de ensino com contrato temporário, em condições totalmente adversas, como: lecionar em várias turmas num mesmo ano letivo; conviver com relações de disputa, tendo em vista as relações hierárquicas presentes no ambiente escolar entre professor efetivo, professor temporário e gestores. Indicaram, também, a necessidade de apoio aos professores iniciantes e o investimento em políticas de formação e valorização para estimular entrada na carreira e a permanência dos professores na escola. (SILVA, 2017).

Marli André (2017), no trabalho intitulado Inserção profissional de egressos de programas de iniciação à docência, apresentou os dados da primeira etapa de pesquisa realizada 
que objetivou compreender como egressos de três Programas de iniciação à docência - Pibid, Bolsa Alfabetização e Residência Pedagógica vivenciam sua inserção profissional. Na primeira etapa da pesquisa, para a caracterização dos egressos, bem como o mapeamento de sua destinação profissional, foi organizada uma survey, que por via de um questionário eletrônico, foi encaminhada a 3095 egressos desses Programas em 18 IES, sendo 08 federais, 02 estaduais, 05 comunitárias e 03 privadas, de nove estados, das regiões Nordeste, Centro Oeste, Sul e Sudeste do país. O retorno dos dados, após cinco emissões do questionário, foi de cerca de 40\%, num total de 1237 participantes.

Os resultados desta etapa da pesquisa apresentaram o seguinte perfil dos egressos dos três Programas de iniciação à docência: i) são professores iniciantes jovens e a grande maioria frequentou o ensino fundamental e médio todo em escola pública; ii) Cursaram a licenciatura em diversas áreas; iii) e, em 2016, 67\% estavam atuando como docentes na educação básica grande parte desses, em escolas públicas (60\%), fato que revela um retorno do investimento do governo federal e das Instituições de Ensino Superior. Nesse sentido, os três Programas analisados na pesquisa constituem um avanço na formação inicial no sentido de diminuir a distância entre a formação acadêmica e o espaço de trabalho, favorecendo melhor articulação entre teoria e prática e contribuindo para a elevação da qualidade dos cursos de licenciatura (ANDRÉ, 2017).

Para a autora, quando os professores iniciantes chegam às escolas, trazem os conhecimentos formulados durante seu percurso estudantil, seja na educação básica ou na formação superior, mas ainda têm muito que aprender na nova posição - a de professor em uma sala de aula ensinando seus alunos. Desse modo, os professores iniciantes vão aprendendo a conduzir a sala de aula, à medida que ensinam. Aprendem, ainda, nesse processo, a lidar com os conteúdos, com o comportamento dos alunos, a se relacionar com os pais e com seus pares e tantas outras aprendizagens necessárias à docência (ANDRÉ, 2017).

De maneira geral, as pesquisas sobre a inserção profissional do docente na carreira focam no seu desenvolvimento profissional, investigando a prática pedagógica, as dificuldades, as tensões, relacionando-as com a formação inicial. Na sua maioria, essas pesquisam parecem seguir uma tendência que responsabiliza a formação inicial pelas dificuldades encontradas nos anos iniciais do exercício da profissão. Diante desse quadro, é pertinente questionarmos: não seria a docência toda ela marcada por sentimentos de insegurança, dilemas e crises de incertezas? De que modo esses estudos ajudam a problematizar o tema professor iniciante ao pensar, por exemplo, como essas experiências de si operam na constituição do tornar-se um professor?

Inquietados por provocações, e como pesquisadores do campo da formação de professores, consideramos importante e necessário ampliar e aprofundar as pesquisas sobre a inserção profissional na carreira docente, lançando outros olhares sobre a problemática, a partir de outras abordagens teóricometodológicas no sentido de trazer novos elementos e novas contribuições que possam ajudar a compreender esse processo tão importante para esse campo de pesquisa, que é a iniciação profissional na carreira.

Assim, trazemos, aqui, um recorte de uma pesquisa realizada com professores recémformados que estão iniciando na profissão - entre um e quatro anos de docência - no Ensino Fundamental II e Ensino Médio, que teve como objetivo investigar e compreender as ressonâncias do currículo na formação e no desenvolvimento de professores iniciantes. Debruçamo-nos sobre as informações de pesquisa produzidas a partir da seguinte provocação: como os professores nos primeiros anos da profissão veem a prática docente?

Este texto busca, então, analisar as percepções desses professores sobre a prática docente no percurso de inserção profissional no magistério.

\section{Inquietudes sobre a formação - desenho metodológico da pesquisa}

A pesquisa em Educação sempre nos coloca frente a um universo complexo, pois definir os caminhos para serem trilhados é ter que fazer escolhas, nem sempre fáceis. Desse modo, longe de pretender certezas metodológicas, procuramos pensar em procedimentos que pudessem nos ajudar a trilhar os caminhos da pesquisa, interrogando melhor o objeto de estudo. Esse processo é sempre pedagógico porque nos ensina como fazer ou como fazemos uma pesquisa. 
Nesse sentido, tomando como ponto de partida a questão de pesquisa e os objetivos definidos, optamos pela abordagem qualitativa por considerá-la como um universo de produção humana e suas relações, representações e intencionalidades, trabalhando com os significados, os motivos, as aspirações, as crenças e as atitudes vinculadas ao humano. (MINAYO, 2007). Assim, selecionado o campo empírico - o curso de Licenciatura em Letras de uma Universidade pública - e os colaboradores da pesquisa - egressos desse curso em atuação na docência -, foi feita a aplicação de questionário aberto aos participantes do estudo.

As questões abertas foram elaboradas para que os sujeitos pudessem se expressar a partir de pequenas narrativas, "estimulando a produção de tecidos de informação, e não de respostas pontuais." (GONZÁLEZ REY, 2005, p. 43). A seleção dos participantes se deu em um processo estruturado em critérios. O primeiro deles foi ter concluído o curso entre 2010 e 2015 - período com os últimos registros de conclusão na Secretaria Acadêmica. Essa delimitação foi necessária em razão da implantação do currículo redimensionado que aconteceu a partir de 2007, na Universidade pesquisada, totalizando em 94 concluintes - 88 mulheres e 06 homens.

O critério seguinte foi estar como docentes de Língua Portuguesa e/ou Redação nos anos finais do Ensino Fundamental ou Língua Portuguesa e Literatura Brasileira no Ensino Médio. O levantamento foi feito a partir de contatos eletrônicos (um total de 68), para enviar questionário semiestruturado elaborado em consonância com os objetivos da pesquisa.

Foram devolvidos 27 questionários, dos quais quatro não responderam, justificando que não estavam atuando como professores. Dos 23 questionários respondidos, 10 foram descartados porque os professores estavam atuando nos anos iniciais do Ensino Fundamental, como docentes e/ou coordenadores pedagógicos. Então, 13 foram considerados por atenderem aos critérios estabelecidos na pesquisa - 11 mulheres e 02 homens, todos licenciados em Letras Língua Portuguesa. Os sujeitos são identificados, neste texto, com nomes fictícios, conforme definido no Termo de Consentimento Livre e Esclarecido (TCLE).

\section{Paradoxos da inserção profissional na prática docente}

Para analisar as percepções de professores iniciantes sobre a prática docente, conforme anunciado, anteriormente, debruçamonos sobre as informações de pesquisa que estão relacionadas à questão mobilizadora deste artigo: como os professores no início da profissão docente veem a sua prática docente. São esses resultados, então, que discutiremos a partir de agora.

Em uma das questões do questionário enviado aos sujeitos, provocamos os partícipes da pesquisa com a frase "Ser professor na contemporaneidade é..." No quadro a seguir, apresentamos uma síntese de respostas dadas pelos jovens professores.

Quadro 1. Síntese de respostas dos sujeitos

\begin{tabular}{|c|c|c|}
\hline Sujeitos & Tempo na docência & Ser professor na contemporaneidade é... \\
\hline Marta & 1 ano & $\ldots$ um desafio paradoxal \\
\hline Laura & 1 ano & $\ldots$ muito difícil \\
\hline Ane & 1 ano e meio & $\ldots$ lidar com universo de identidades diversas e fragmentadas \\
\hline Carla & 1 ano e meio & $\ldots$ uma tarefa muito complexa \\
\hline Jane & 2 anos & $\ldots$ um desafio a cada aula \\
\hline Patrícia & 2 anos & $\ldots$ um eterno aprender \\
\hline Simone & 2 anos & $\ldots$ superar os desafios da sala de aula \\
\hline Joana & 3 anos & $\ldots$ abrir-se para o novo \\
\hline Antônia & 3 anos & $\ldots$ viver a complexidade todos os dias \\
\hline João & 3 anos & $\ldots$ ser um mediadiplo \\
\hline Luiz & 3 anos & $\ldots$ é muito complito condo \\
\hline Sara & 3 anos & $\ldots$ surpreendente \\
\hline Gisele & 4 anos &
\end{tabular}

FONTE: Elaborado pelos Autores (2017)

\footnotetext{
${ }^{1}$ Eis a inspiração para o título deste texto: para além de um relato de uma professora iniciante, um desconforto que nos segue, por anos, no exercício da profissão docente.
} 
Os professores iniciantes investigados são jovens, recém-formados e têm entre um e quatro anos de docência. Suas percepções sobre ser professor evidenciam as marcas de um tempo presente assinalado por uma aceleração vertiginosa da informação, por mudanças e incertezas que vêm alterando a sociedade em todos os aspectos. As questões contemporâneas da sociedade demarcam novas condições sociais, políticas e culturais, bem como mudanças na subjetividade dos indivíduos. Conforme nos diz Paraíso (2014, p. 28),

[...] este novo tempo vive mudanças significativas na educação porque mudaram as condições sociais, as relações culturais, as racionalidades. Mudaram os espaços, a política, os movimentos sociais e as desigualdades. Mudaram também as distâncias, as geografias, as identidades e as diferenças. Mudaram as pedagogias e os modos de ensinar e aprender. Mudaram os pensamentos, os raciocínios, os modos de "descolonizar" os mapas culturais.

Nesse cenário, a educação escolar tem sido desafiada a pensar a sua finalidade social, sua estrutura organizacional e sua política didático-pedagógica. $\mathrm{O}$ mundo cada vez mais reconfigurado está adentrando com mais rapidez aos espaços educacionais, os quais não estão conseguindo dialogar com as novas dinâmicas e com as visões plurais que permeiam os humanos contemporâneos. Em outras palavras, o mundo que está além dos muros da escola cresceu muito rapidamente e está se tornando bem diferente daquele que as escolas estão acostumadas a mostrar.

Assim, outro mundo é gestado em sintonia com as tecnologias da informação e comunicação e provoca uma crise no centro da educação escolar, colocando em xeque os dispositivos educacionais, como o currículo, os conteúdos, as metodologias de ensino, bem como o próprio modelo de ensino implantado nos limiares da modernidade. Em uma sociedade como a nossa, marcada pela diversidade em todos os aspectos, os processos educacionais não podem ser sustentados em pilares que visam à homogeneidade. Moreira (2010, p. 176) nos diz que "nossas sociedades contemporâneas são inegavelmente multiculturais. Nelas, as diferenças derivadas de dinâmicas sociais como classe social, gênero, etnia, orientação sexual, cultura, religião expressam-se nas distintas esferas sociais".

De forma sintética, apresentamos alguns apontamentos sobre a contemporaneidade para compreendermos o sentido do ser professor apresentado pelos professores iniciantes na pesquisa. Ao retratarem a profissão como paradoxal, desafiante, complexa, múltipla, surpreendente, os sujeitos dizem de um lugar em que convivem diariamente com esses aspectos com mais intensidade: a escola. O paradoxo começa quando eles chegam a este espaço, recém-formados, e, de repente, descobrem que precisam aprender a ensinar porque da maneira como eles pensaram na formação inicial nem sempre funciona. Os relatos a seguir nos ajudam a compreender e aprofundar nessa questão.

Quando comecei a dar aulas, tive a sensação que tinha que aprender muita coisa! Pra mim, os primeiros contatos com a sala de aula como professora foram difíceis; $e$, ainda hoje, por vezes, tenho muitas dúvidas na hora de tomar algumas decisões. (Patrícia, relato escrito, 2017) (grifos nossos).

[...] às vezes entramos até em colapso, principalmente, depois da conclusão do curso, que já somos profissionais $e$ sentimos um "peso" de responsabilidade, quando assumimos uma sala de aula. E assim, vêm as perguntas como: Que professora eu gostaria de ser? O que eu devo fazer diante de cada situação difícil da sala de aula? (Carla, relato escrito, 2017) (grifos nossos).

[...] sinto que as discussões sobre didática, avaliação, currículo foram pouco 
efetivas a ponto de se tornarem uma dificuldade que tive que superar a duras penas, já imersa no contexto de sala de aula. (Joana, relato escrito, 2017).

Os grifos nos relatos buscam mostrar que os primeiros anos da docência são marcados por dificuldades, angústias e dúvidas com os desafios que aparecem, diariamente, no exercício da profissão. Esses aspectos reforçam a ideia dos iniciantes na profissão de que a docência, na contemporaneidade, é uma atividade complexa. $\mathrm{Na}$ literatura, alguns autores caracterizam este momento como o choque de realidade (HUBERMAN, 2000, TARDIF, 2014).

Marcelo García (2010) nos diz que a iniciação ao ensino ocorre nos primeiros anos, nos quais os professores fazem a transição de estudantes para docentes. Segundo esse autor, esse período é marcado por tensões e aprendizagens intensivas em contextos que, geralmente, são desconhecidos pelos professores iniciantes. Além do conhecimento profissional, os professores iniciantes precisam manter certo equilíbrio pessoal. Mariano (2006, p. 44) descreve os primeiros passos do professor iniciante da seguinte forma,

Esse choque é marcado
pelo sentimento de
sobrevivência, quando o
iniciante se questiona: o
que estou fazendo aqui?
Em contrapartida, os
professores podem
experimentar a
sentimento de descoberta,
o sentir-se profissional, ter
a sua sala de aula. É esta
descoberta a mola
propulsora para a
permanência na profissão.

É importante destacar, aqui, que as mudanças que estão acontecendo na sociedade nos últimos tempos têm provocado alterações na escola como um todo. Por esta razão, talvez não seja mais apropriado associar as tensões, sentimento de insegurança, superação de desafios e novas aprendizagens somente aos professores iniciantes. Ousamos, então, dizer que essas características acabam perpassando por todos os professores, independente do tempo de atuação na escola. Nesse sentido, a formação permanente dos professores se configura como uma condição necessária e fundamental para dar suporte à escola nesse contexto de complexidade.

Um aspecto recorrente nas impressões dos professores iniciantes investigados sobre a prática docente refere-se à formação inicial. Quando solicitados para destacar lacunas que identificam na sua prática docente, obtivemos os seguintes relatos,

Considero que minha formação foi insatisfatória em relação à docência, diante dos desafios da sociedade contemporânea. o comportamento dos estudantes não é mais o mesmo. Instalou-se o celular, as diversas fontes de comunicação, os conflitos oriundos do vício pelas drogas; (...) tudo isso repercute intensamente na escola. Ao final do curso de Letras, como de qualquer outro curso, muitos frustram com a profissão. (Carla, Relato escrito, 2017)

Percebi que tenho muito pouco do necessário para trabalhar com alunos especiais na sala de aula, haja vista que temos muitos casos de alunos surdos, com Síndrome de Down e outras dificuldades físicas; sinto dificuldade, também, de trabalhar com as questões de gênero $e$ sexualidade (Antônia, relato escrito, 2017).

A Universidade se preocupou muito com conteúdos, cargas horárias entre outras "obrigações" e se esqueceu da formação enquanto ser humano para trabalhar com outro ser humano. (Sara, relato escrito, 2017)

Há nesses relatos uma provocação por parte dos sujeitos quanto ao percurso formativo na Universidade. Revelam uma concepção de formação que valoriza o espaço acadêmico sem estabelecer um diálogo e interações com as 
questões que estão borbulhando nas escolas. Nesse sentido, ao analisarmos o Projeto do Curso, identificamos que a organização curricular "busca priorizar a prática pedagógica desde o seu início, incentivando a participação discente em atividades de pesquisa e extensão, promover a integração entre essas duas atividades e a de ensino" (UNEB, 2007, s/p). No entanto, de modo geral, as ementas não indicam como se dará essa reflexão entre a teoria e a prática.

A apresentação das ementas na matriz curricular, na primeira metade do curso, sinaliza que a execução do currículo contradiz a própria concepção de relação teoria e prática apresentada no Projeto; bem como nas políticas de formação docente. Os resquícios da concepção tradicional de formação são perceptíveis: é preciso garantir no início uma sólida formação teórica aos alunos para que, do meio para o fim do curso, aconteça a aplicabilidade do conhecimento, no componente Estágio Supervisionado. Para Barretto (2015, p. 688), "[...] a concepção dominante é a de que para ser um bom professor basta que ele domine os conhecimentos das disciplinas que deve ensinar. Falta aos cursos, de modo geral, um foco claro na docência".

Mais uma vez destacamos a importância da formação como condição para pensar a docência articulada com as demandas da contemporaneidade: formação inicial e no exercício da profissão. Para André (2012, p. 116), "[...] reconhecer que a formação não se encerra na conclusão dos cursos de licenciatura, mas deve prosseguir ao longo da carreira, é um passo importante para que o iniciante não desanime diante das dificuldades". Assim, são necessários Programas de apoio e acompanhamento aos professores iniciantes que possam auxiliá-los nessa fase de transição.

Imbernón (2016), pesquisador que estuda a formação docente nos países da Europa e América Latina, destaca que, embora muitos aspectos contextuais, sociais e educacionais separam esses dois universos, há que reconhecer que, assim como os europeus, os países latinoamericanos avançaram muito em formação e capacitação de docentes. Entretanto, diz ele, há uma insistência maior em capacitar do que desenvolver profissionalmente o professorado. A formação se legitimará quando contribuir para o desenvolvimento profissional dos docentes no âmbito do trabalho. Na avaliação do autor, o professorado da América Latina está assumindo um alto grau de capacitação, mas ainda se mantém em um desenvolvimento profissional muito pobre.

Nessa perspectiva, é importante considerar o período de inserção profissional na carreira docente como um período diferenciado no caminho para se tornar um professor, sendo necessário um acompanhamento formativo. Afinal, "não é um salto no vazio entre a formação inicial e a formação continuada, mas antes tem um caráter distintivo e determinante para conseguir um desenvolvimento profissional coerente e evolutivo" (MARCELO GARCÍA, 2010, p. 28-29).

A análise dos relatos dos professores iniciantes apresentou, também, indícios de relações de poder no ambiente escolar. Os principiantes revelaram o desejo de fazer uma prática pedagógica comprometida com o processo ensino e aprendizagem. Chegam à escola, motivados, e com o desejo de contribuir para o crescimento dos alunos, conforme relatos a seguir,

Eu discordo de algumas
maneiras da escola e do
coordenador, mas eu não
posso entrar em confronto,
por " $n$ " motivos. Eu não
quero ser melhor, mas
queria fazer diferença e
praticar o que eu conheci
durante quatro anos de
Universidade (Carla, relato
escrito, 2017).
Muitas vezes a nossa
maneira de conduzir as
aulas não é bem vista
pelos outros professores e
gestores da escola. (Luiz,
relato escrito, 2017).

Podemos inferir que a condição de professoras iniciantes de Carla e Luiz é um dos motivos para não contrapor às ideias que estão sacramentadas no contexto escolar. Na escola, as relações de poder operam na organização do processo educacional, estabelecendo, por exemplo, que os melhores horários sejam destinados aos professores experientes e as turmas consideradas mais difíceis - aquelas com alunos repetentes, distorção idade/série, problemas de indisciplina - sejam destinadas aos jovens professores. Os experientes assumem as turmas consideradas como as melhores na avaliação da escola. Nas decisões importantes da 
instituição, a voz dos experientes tem preponderância com a justificativa de que conhecem bem a realidade da sala de aula.

Assim, as relações pedagógicas que se desenvolvem entre os professores iniciantes e experientes no contexto escolar são, originalmente, relações de poder. Diante disso, é importante analisar o modo como o poder se exerce nas práticas escolares em que se inserem os professores iniciantes. Para Foucault (2002), certas práticas que se legitimam, numa pretensa defesa da sociedade, separam grupos, formam objetos e domínios, produzem verdades, forjam juízos e sujeições, operando, ao mesmo tempo, pelas resistências no mesmo jogo de poder e de saber em que elas se efetivam.

As relações de poder estabelecidas na escola definem, então, os papéis entre os professores novatos e os professores experientes. Marcelo García (2010) destaca que os professores, de modo geral, enfrentam, sozinhos, a tarefa de ensinar. Segundo ele, "somente os alunos são testemunhas da atuação profissional dos docentes" (MARCELO GARCÍA, 2010, p.15).

Nesse percurso da iniciação na profissão docente, os professores também revelaram que a prática docente pode ser de descoberta, do experienciar e do experimentar. Acreditamos que essas possibilidades surgem quando os iniciantes ousam resistir às configurações de poder que circulam e operam na escola. Assim, eles relatam,

[...] enquanto docente, é gratificante experimentar e ver que quando as coisas dão certo, a gente "dá conta da tarefa" (Laura, relato escrito, 2017).

[...] a sala de aula é o laboratório do professor. (Simone, relato escrito, 2017).

Podemos perceber, assim, que esses professores iniciantes querem construir seu referencial de docência, inovar na sua prática pedagógica, mostrar seus modos de ser um professor. Eles se enxergam de diferentes formas e têm diferentes expectativas em relação ao seu processo de iniciação profissional. Talvez, por isso, não procuram a imitação como caminho para essa construção, mas a ousadia na descoberta de possibilidades de como interagir com os alunos, planejar as metodologias de ensino, a avaliação e o trato com a (in) disciplina na sala de aula. Pode ser que seja uma forma de resistência que o professor iniciante utiliza frente aos discursos de verdade instituídos no contexto educacional.

A análise dessas informações evidencia que a inserção profissional na carreira docente é um mosaico de muitas peças que operam na constituição do sentido da docência pelo professor iniciante. Nesse processo, vão se constituindo, e são constituídos, cada um a seu jeito, como professores, mesclando variadas situações desde as suas vivências na escola como estudante, passando pela formação inicial e juntando-se às experiências - todas elas - da escola e da comunidade em que estão inseridos.

Em síntese, podemos dizer que, numa conjuntura social e educacional marcada por incertezas e mudanças, os professores iniciantes veem a profissão docente como paradoxal: precisam ao mesmo tempo ensinar e aprender como ensinar; precisam ensinar o outro e aprender a lidar com o outro num espaço em que é visto com desconfiança. Veem a profissão docente como complexa: precisam ser múltiplos professor, amigo, facilitador, conselheiro...; precisam lidar com um universo de identidades diversas e fragmentadas; precisam abrir-se para o novo - que também é complexo. Por fim, veem a profissão como surpreendente, afinal ela feita em torno da vida e não há nada mais surpreendente no mundo do que a vida.

\section{Um eterno aprender...}

A partir dos resultados da investigação e da relação com a literatura consultada, podemos destacar que o início da vida profissional, na docência, é caracterizado pelo "choque de realidade", pelos dilemas e desafios em aprender a docência exercitando-a; bem como pelo sentimento de insegurança e incompletude em meio às relações de poder que operam no contexto escolar. Há, também, nesse percurso, o desejo de fazer a diferença, de experimentar o novo.

Os paradoxos que marcam a iniciação na carreira docente refletem, em nossa análise, o dilema do processo educacional na contemporaneidade. De um lado, ainda operam na escola apontamentos históricos da constituição da prática docente, associados à Pedagogia religiosa - centrada na transmissão do conhecimento que referenciou o surgimento da escola e da figura do professor -, e à Pedagogia tecnicista - vinculada às concepções do racionalismo científico. Esses aspectos estão 
presentes, também, na formação inicial de professores, conforme destaca Barretto (2015, p. 687) quando diz que "nos modelos de formação de professores prevalecem arquétipos que remontam aos períodos fundacionais dos sistemas de ensino e explicam a permanência de desequilíbrios históricos na composição dos currículos das licenciaturas".

Por outro lado, as realidades sociais que constituem as escolas, hoje, provocam a inquietação e o desejo de que o processo educativo seja significativo e coerente com as dinâmicas do tempo atual. Como em um campo de disputas, essas perspectivas discursivas produzem, na percepção dos professores iniciantes, a insegurança e a complexidade da prática docente.

Como nos tempos atuais, assumimos que os saberes são provisórios, que as identidades dos sujeitos se alteram a todo o momento e que a docência não é estática, nem acabada, pelo contrário, múltipla e surpreendente. Para DinizPereira (2010), as reflexões individuais e/ou coletivas que os professores fazem sobre sua (s) experiência(s) talvez tenham um impacto maior no início da carreira docente, pois este é um momento de indefinição e conflitos no percurso formativo do professor. Nesse contexto, os professores iniciantes - e acreditamos que os experientes também - veem-se desafiados a aprender sempre e a abrir-se para o novo. A questão que se coloca, então, é: mas o que é esse novo?

Em nossa compreensão, não existe um modelo definido para o novo. $E$ isso precisa ser mais bem debatido na formação e na escola. Abrir-se para o novo é, no nosso entendimento, romper com modelos prontos, inventar e reinventar sempre a prática docente. Nesse processo, os professores devem assumir o protagonismo de sua profissionalização, constituindo-se e reinventando-se, permanentemente. Para Imbernón (2016, p. 127), "não há melhor grupo que aquele que reflete sobre si mesmo para melhorar. E O professorado é o protagonista da mudança". Desse modo, é possível criar possibilidades outras em parceria com os sujeitos nos contextos nos quais a prática docente é exercida. Exercer a docência é, então, como dizem os professores iniciantes, um eterno aprender.

Nessa perspectiva, as informações da pesquisa nos permitem dizer que é importante aprofundar os estudos sobre os professores no início da carreira no sentido de levantar outros questionamentos sobre o tema, como: os problemas e dificuldades apontados não seriam os mesmos enfrentados por todos os docentes na escola, hoje, independente do tempo de serviço? $\mathrm{Ou}$ serão esses problemas e dificuldades decorrentes dos modos como os iniciantes são subjetivados nas relações de poder que se estabelecem no contexto escolar? Quais outros modos são possíveis para a iniciação na docência?

Tais questionamentos, bem como o que mobiliza a construção deste texto, precisam entrar na pauta dos cursos de formação de professores e não apenas nos projetos dos pesquisadores. Assim, esperamos que as considerações e provocações aqui apresentadas estimulem e fortaleçam os debates $e$ as discussões sobre a inserção profissional de docentes na carreira. De nossa parte, estamos abertos ao diálogo.

\section{REFERÊNCIAS}

ALVES-MAZZOTTI, Alda Judith. Revisão de bibliografia. In: ALVES-MAZZOTTI, Alda Judith, GEWANDSZAJDER, Fernando. 0 método nas ciências naturais e sociais: pesquisa quantitativa e qualitativa. 2. ed. São Paulo: Pioneira, 1999. p 179-188.

ANDRÉ. M. E. D. A. Políticas e Programas de apoio aos professores iniciantes no Brasil. Cadernos de Pesquisa. V. 42 , n. 145 , p. $112-129$, jan./abr. 2012. DOI: $10.1590 /$ S0100-15742012000100008. Disponível em: http://www.scielo.br/scielo.php?script=sci_arttex $\mathrm{t} \& \mathrm{pid}=\mathrm{S} 0100$

$15742012000100008 \&$ Ing=pt\&tlng=pt. Acesso em: 19/08/2018.

ANDRÉ. M. E. D. A.. Inserção profissional de egressos de programas de iniciação à docência. In: REUNIÃO ANUAL DA ANPEd, 38., São Luis. Anais... São Luís/MA: UFMA, 2017. Disponível em:

http://38reuniao.anped.org.br/sites/default/files/ resources/programacao/trabalhoencom_38anpe d_2017_gt08i_textomarlyandre.pdf Acesso em 20/08/2018.

BARRETTO. Elba S. de Sá. Políticas de formação docente para a educação básica no Brasil: embates contemporâneos. Revista Brasileira de Educação. v. 20 n. 62, p. 679 -701, jul.-set. 2015. 
DOI:

Disponível:

http://www.scielo.br/scielo.php?script=sci_arttex $\mathrm{t} \& \mathrm{pid}=\mathrm{S} 1413-$

24782015000300679\&Ing=pt\&tlng=pt. Acesso em: 19/08/2018.

CALIL, A. M. G. C.; ANDRÉ, M. E. D. A. Uma política de formação voltada aos professores iniciantes de Sobral - CE. Rev. Diálogo Educ. Curitiba, v. 16, n. 50, p. 891-909, out./dez. 2016.

CAVACO, Maria Helena. Ofício do professor: o tempo e as mudanças. In: Antonio Nóvoa (org). Profissão Professor. p. 155-191. Porto: Porto Editora, 1999.

DINIZ-PEREIRA, J. E. A epistemologia da experiência na formação de professores: primeiras aproximações. Form. Doc., Belo Horizonte, v. 02, n. 02, p. 83-93, jan./jul. 2010. Disponível em: https://revformacaodocente.com.br/index.php/r bpfp/article/view/v2n2_2f Acesso em: 26/11/2018.

FOUCAULT, Michel. Vigiar e Punir: nascimento da prisão. Petrópolis: Vozes, 2002.

GONZÁLEZ REY, F. Pesquisa qualitativa e subjetividade: os processos de construção da informação. São Paulo: Pioneira Thomson Learning, 2005.

GUARNIERI, Maria Regina. O início na carreira docente: pistas para o estudo do trabalho do professor. In: GUARNIERI, Maria Regina (Org.). Aprendendo a ensinar: o caminho nada suave da docência. p. 5-24. 2a ed. Campinas: Autores Associados, 2005.

HUBERMAN, M. O ciclo de vida profissional dos professores. In: NÓVOA, A. (Org.). Vidas de professores. p. 31-61. 2a ed. Porto: Porto, 2000.

IMBERNÓN, Francisco. Qualidade do ensino e formação do professorado: uma mudança necessária. São Paulo: Cortez, 2016.

LIMA, Emília Freitas de. A construção do início da docência: reflexões a partir de pesquisas brasileiras. Cadernos de Educação. Santa Maria, v.29, n.2, p.85-98, 2004.
MACHADO, Laêda Bezerra. Profissão docente: o consenso das representações sociais de professores iniciantes. In: REUNIÃO ANUAL DA ANPEd, 37., 2015. Anais... UFSC - Florianópolis, $2015 . \quad$ Disponível em http://www.anped.org.br/sites/default/files/trab alho-gt20-3733.pdf Acesso: 29/09/2017.

MARCELO GARCÍA, C. O professor iniciante, a prática pedagógica e o sentido da experiência. Revista Brasileira de Pesquisa sobre Formação Docente. Belo Horizonte, v.03, n.03, p.11-49, $2010 . \quad$ Disponível em: http://formacaodocente.autenticaeditora.com.br Acesso em: 07/09/2017.

MARCELO GARCÍA. Politicas de inserción en la docência: de eslabón perdido a puente para el desarollo profissional docente. PREAL, documento n. 52, 2011.

MARIANO, A. L. S. Aprendendo a ser professor no início da carreira: um olhar a partir da ANPEd. In: REUNIÃO ANUAL DA ANPED, 28. Caxambu. Anais... Caxambu: ANPEd, 2006. Disponível em: http://www.anped.org.br/reunioes/28/inicio.htm . Acesso em 20/08/2018.

MINAYO, Maria Cecília de Souza (org.) Pesquisa social. Petrópolis: Vozes, 2007.

MOREIRA, A. F. B. A recente produção científica sobre currículo e multiculturalismo no Brasil (1995- 2000): avanços, desafios e tensões. In: MOREIRA, Antonio Flávio Barbosa; PARAíso, Marlucy Alves (Orgs.). Pesquisador em currículo. Belo Horizonte: Autêntica Editora, 2010.

PAPI, Silmara de Oliveira. Professoras iniciantes bem-sucedidas: elementos de seu desenvolvimento profissional. In: REUNIÃO ANUAL DA ASSOCIAÇÃO NACIONAL DE PESQUISA EM EDUCAÇÃO, 34., Natal. Anais... Natal: Anped, 2011.

PARAísO, Marlucy Alves. Metodologia de pesquisas pós-críticas em educação e currículo: trajetórias, pressupostos, procedimentos e estratégias analíticas. In: PARAísO, M. A.; MEYER, D. E. Metodologia de Pesquisas Pós-críticas em Educação. p. 25-47. 2a ed. Belo Horizonte, MG: Mazza Edições, 2014. 
SILVA. Kátia Augusta C. P. C. da. Professores em início de carreira: as dificuldades e descobertas do trabalho docente no cotidiano da escola. In: REUNIÃO ANUAL DA ANPEd, 38., São Luis,. Anais... São Luís: UFMA, 2017. Disponível em: http://38reuniao.anped.org.br/sites/default/files/ resources/programacao/trabalhoencom_38anpe d_2017_gt08_i_textokatiacurado.pdf Acesso em 20 ago. 2018.

TARDIF, Maurice. Saberes docentes e formação profissional. Petrópolis, RJ: Vozes, 2014.

UNEB, Projeto Pedagógico do Curso de Letras. Universidade do Estado da Bahia. Departamento de Ciências Humanas, Campus VI - Caetité/BA, 2007.

VAILLANT, Denise.; MARCELO GARCIA, C. Ensinando a ensinar: as quatro etapas de uma aprendizagem. Curitiba: UTFPR, 2012.

Recebido para avaliação: 06/09/2018

Revisado em: 29/11/2018

Aceite Final: 29/11/2018 